\title{
Myocardium protection against ischemic-reperfusion injury by nitric oxide supplied to the extracorporeal circulation line during cardiopulmonary bypass (experimental study)
}

\author{
Nikolay O. Kamenshchikov \\ Research Institute of Cardiology, Tomsk National Research Medical Center, Russian Academy of Sciences, Tomsk, Russian Federation, 2018
}

Aim

Methods

Results

Conclusion

$$
\text { The }
$$

The data obtained during the experiment demonstrate the presence of
cardioprotective properties of nitric oxide delivered to the extracorporeal
circulation line when simulating myocardial ischemic-reperfusion injury.
These properties manifest themselves as a 15\% decrease of the infarction tissue perfusion during cardiopulmonary bypass. Intraoperative myocardial
protection by nitric oxide in patients operated with cardiopulmonary bypass should be the object of further clinical research. protective properties of nitric oxide delivered to the extracorporeal
line when simulating myocardial ischemic-reperfusion injury. perties manifest themselves as a $15 \%$ decrease of the infarction zone-risk area ratio, a fewer number of arrhythmias and improvement of

\begin{tabular}{|c|c|c|c|c|}
\hline Phase & Arrhythmia & Main group & Control group & $\mathrm{p}$ \\
\hline $10 \mathrm{~min}$ of ischemia & $\begin{array}{l}\text { no ventricular arrhythmia or rare polytopic ventricular extra } \\
\text { systole }\end{array}$ & $5(50 \%)$ & $6(60 \%)$ & 0.5 \\
\hline $10 \mathrm{~min}$ of ischemia & polytopic and polymorphic ventricular extra systole & $2(20 \%)$ & $9(90 \%)$ & 0.003 \\
\hline $10 \mathrm{~min}$ of ischemia & ventricular fibrillation & 0 & $1(10 \%)$ & 0.5 \\
\hline $35 \mathrm{~min}$ of ischemia & $\begin{array}{l}\text { no ventricular arrhythmia or rare polytopic ventricular extra } \\
\text { systole }\end{array}$ & $5(50 \%)$ & $6(60 \%)$ & 0.5 \\
\hline $35 \mathrm{~min}$ of ischemia & polytopic and polymorphic ventricular extra systole & $1(10 \%)$ & $7(70 \%)$ & 0.001 \\
\hline 35 min of ischemia & ventricular fibrillation & $1(10 \%)$ & $1(10 \%)$ & 1 \\
\hline 45 min of reperfusion & $\begin{array}{l}\text { no ventricular arrhythmia or rare polytopic ventricular extra } \\
\text { systole }\end{array}$ & $5(50 \%)$ & $4(40 \%)$ & 0.5 \\
\hline 45 min of reperfusion & polytopic and polymorphic ventricular extra systole & $2(20 \%)$ & $8(80 \%)$ & 0.012 \\
\hline 45 min of reperfusion & ventricular fibrillation & 0 & $4(40 \%)$ & 0.04 \\
\hline
\end{tabular}

Nitric oxide delivery into the extracorporeal circulation line and its impact on arrhythmia occurrence during ischemia and reperfusion

Pearson Chi-Square test was used. Data are presented as n (\%) 